\title{
Polyphenolic compounds appear to limit the nutritional benefit of biofortified higher iron black bean (Phaseolus vulgaris L.)
}

Elad Tako ${ }^{1 *}$, Steve E Beebe ${ }^{2}$, Spenser Reed ${ }^{1}$, Jonathan J Hart ${ }^{3}$ and Raymond P Glahn ${ }^{1}$

\begin{abstract}
Background: Our objective was to determine if a biofortified variety of black bean can provide more bioavailable-iron

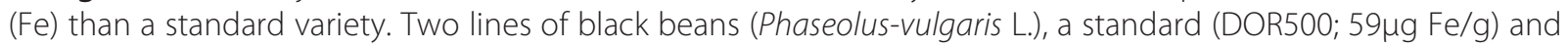
biofortified (MIB465; 88 $\mu \mathrm{g} \mathrm{Fe/g)} \mathrm{were} \mathrm{used.} \mathrm{The} \mathrm{DOR500} \mathrm{is} \mathrm{a} \mathrm{common} \mathrm{commercial} \mathrm{variety,} \mathrm{and} \mathrm{the} \mathrm{MIB465} \mathrm{is} \mathrm{a} \mathrm{line}$ developed for higher-Fe content. Given the high prevalence of Fe-deficiency anemia worldwide, it is important to determine if Fe-biofortified black beans can provide more absorbable-Fe.
\end{abstract}

Methods: Black bean based diets were formulated to meet the nutrient requirements for the broiler (Gallus-gallus) except for Fe (dietary Fe-concentrations were $39.4 \pm 0.2$ and $52.9 \pm 0.9 \mathrm{mg} / \mathrm{kg}$ diet, standard vs. biofortified, respectively). Birds ( $n=14)$ were fed the diets for 6-weeks. Hemoglobin-(Hb), liver-ferritin and Fe-related transporter/ enzyme gene-expression were measured. Hemoglobin-maintenance-efficiency and total-body-Hb-Fe values were used to estimate Fe-bioavailability.

Results: Hemoglobin-maintenance-efficiency values were higher $(\mathrm{P}<0.05)$ in the group consuming the standard-Fe beans on days 14, 21 and 28; indicating a compensatory response to lower dietary-Fe. Final total-Hb-Fe body content was higher in the biofortified vs. the standard group (26.6 \pm 0.9 and $24.4 \pm 0.8 \mathrm{mg}$, respectively; $\mathrm{P}<0.05)$. There were no differences in liver-ferritin or in expression of DMT-1, Dcyt-B, and ferroportin. In-vitro Fe-bioavailability assessment indicated very low Fe-bioavailability from both diets and between the two bean varieties $(P>0.05)$. Such extremely-low in-vitro Fe-bioavailability measurement is indicative of the presence of high levels of polyphenolic-compounds that may inhibit Fe-absorption. High levels of these compounds would be expected in the black bean seed-coats.

Conclusions: The parameters of Fe-status measured in this study indicate that only a minor increase in absorbable-Fe was achieved with the higher-Fe beans. The results also raise the possibility that breeding for increased Fe-concentration elevated the levels of polyphenolic-compounds that can reduce bean Fe-bioavailability, although the higher levels of polyphenolics in the higher-Fe beans may simply be coincidental or an environmental effect. Regardless, Fe-biofortified beans remain a promising vehicle for increasing intakes of bioavailable-Fe in human populations that consume high levels of these beans as a dietary staple, and the bean polyphenol profile must be further evaluated and modified if possible in order to improve the nutritional quality of higher-Fe beans.

Keywords: Beans, Biofortification, Iron bioavailability, In vitro digestion/Caco- 2 cell model, Broiler chicken, Intestine

\footnotetext{
*Correspondence: et79@cornell.edu

${ }^{1}$ USDA/ARS, Robert W. Holley Center for Agriculture and Health, Cornell

University, Ithaca, NY 14853, USA

Full list of author information is available at the end of the article
} 


\section{Introduction}

Iron $(\mathrm{Fe})$ deficiency is the most common nutrient deficiency worldwide [1]. Iron deficiency is particularly widespread in low-income populations where consumption of meat is low and consumption of cereal grains and legumes which contain inhibitors of iron absorption make up the bulk of a diet with little diversity [2-7]. Thus, a major cause of Fe deficiency is low bioavailability from plant-based diets containing Fe bioavailability inhibitors such as polyphenols [4-9]. In the past, policies aimed to alleviate Fe deficiency anemia have primarily involved the use of dietary Fe supplementation for at-risk populations, food fortification, and diversification of diets. However, these strategies can be difficult to sustain in resource-poor regions due to cost, limited access to health care, the partial availability of centralized food processing facilities required for postharvest crop fortification, and other limiting logistical factors [10-12].

Progress has been made during the last decade to develop cereal and legume lines with a higher Fe content and/or bioavailability [5-9,13-15]. This strategy is known as biofortification [16]. In theory, this effort is expected to improve the Fe status of humans in developing countries as it utilizes the tools of plant breeding and agriculture to enhance the amount of absorbable Fe in staple food crops. Once these lines have been developed and stabilized for traits such as higher Fe concentration and or higher Fe bioavailability, then the nutritional benefits should be driven and provided by agriculture and thus sustainable in terms of cost and benefit.

It was previously shown that the common bean (Phaseolus vulgaris L), provides significant quantities of protein and energy and is a source of vitamins and minerals including $\mathrm{Fe}[7,8,17,18]$. The common bean is an attractive candidate for Fe biofortification because there is genetic variability of Fe concentration and therefore it is possible to breed for significant increases in $\mathrm{Fe}$ concentrations in beans [6-8,19]. Also, Fe concentrations in beans are high relative to the cereals and have the potential to deliver substantially more Fe. In studies with rats, bean genotypes with high $\mathrm{Fe}$ concentrations provided more absorbable Fe than genotypes with lower concentrations of $\mathrm{Fe}[7,8,15,19]$. However, rats are known to be very efficient at absorbing Fe relative to humans, hence these studies have questionable relevance to human nutrition $[5-9,19]$.

In recent years, scientists at CIAT (Centro Internacional de Agricultural Tropical, Cali, Colombia) have developed Fe-biofortified black beans that consistently contain 85-100 $\mu \mathrm{g} \mathrm{Fe/g} \mathrm{bean} \mathrm{(dry} \mathrm{basis),} \mathrm{a} \mathrm{substantial} \mathrm{increase}$ over normal beans which tend to range between 50-60 $\mu \mathrm{g}$ $\mathrm{Fe} / \mathrm{g}$ bean $[5,6,8,20]$. In a previous study using piglets as test subjects, this same high Fe black bean variety provided more Fe for hemoglobin synthesis in Fe deficient pigs than a standard black bean line [5]. This result demonstrated that Fe biofortified beans can enhance Fe status in Fe- deficient pigs even when fed as part of a complete diet where the difference in Fe concentration between the diets was only $12 \mu \mathrm{g} / \mathrm{g}$ and the feeding period was only 5 weeks [5]. In addition, previous studies using poultry have demonstrated that increasing $\mathrm{Fe}$ concentrations in large-seeded, red-mottled beans by about $25 \mu \mathrm{g} / \mathrm{g}$ provides more bioavailable and therefore absorbable $\mathrm{Fe}$ in vitro and in vivo [8]. Also it was concluded that increased Fe concentration can limit the polyphenolic inhibitory effect on Fe absorption provided that polyphenolic content remains constant as Fe content increases [8]. Indeed the combination of a poultry model and an in vitro system such as the in vitro digestion Caco- 2 cell model have been demonstrated to be effective and efficient analytical tools for testing common bean varieties showing significant differences in bioavailability $[5-9,15,21]$.

The objective of the current study was to compare the capacities of biofortified and standard, black bean lines to deliver Fe for $\mathrm{Hb}$ synthesis using a Fe deficient broiler chickens as the in vivo model. If these screening tools indicate that nutritional benefits exist, then human efficacy studies using these lines would be warranted and can proceed with greater confidence of success.

\section{Materials and methods}

\section{Animals, diets and study design}

Sixty Cornish cross fertile broiler eggs were obtained from a commercial hatchery (Moyer's chicks, Quakertown, PA). The eggs were incubated under optimal conditions at the Cornell University Animal Science poultry farm incubator. Upon hatching (hatchability rate was 92\%), chicks were allocated into 2 treatment groups on the basis of body weight, gender and blood hemoglobin concentration (aimed to ensure equal distribution between groups, $\mathrm{n}=14$ ): 1. "Standard Fe": 40\% black bean diet (39 $\mu \mathrm{g} \mathrm{Fe/g);} 2$. "Biofortified Fe": 40\% black bean diet (53 $\mu \mathrm{g} \mathrm{Fe} / \mathrm{g})$. Experimental diets had no supplemental Fe. Diets compositions are shown in Table 1.

Chicks were housed in a total-confinement building ( 1 chick per $0.5 \mathrm{~m}^{2}$ metal cage). Birds were under indoor controlled temperatures and were provided $16 \mathrm{~h}$ of light. Each cage was equipped with an automatic nipple drinker and manual self-feeder. All birds were given ad libitum access to water (Fe content was $0.379 \pm 0.012 \mu \mathrm{g} \mathrm{Fe} / \mathrm{ml}$ ). Feed intakes were measured daily (as from day 1). Iron intakes were calculated from feed intakes and Fe concentration in the diets.

The two black bean lines used in the study were a commercial variety for South America (DOR500, Low-Fe) and a biofortified line (MIB465, High-Fe). Seed was multiplied in Palmira, Colombia under fertile soil conditions 
Table 1 Composition of experimental diets

\begin{tabular}{lcc}
\hline Ingredient & $\begin{array}{c}\text { Standard } \\
\text { bean diet }\end{array}$ & $\begin{array}{c}\text { Biofortified } \\
\text { bean diet }\end{array}$ \\
\cline { 2 - 3 } & $\mathbf{g} / \mathbf{k g}$ (by formulation) \\
\hline Biofortified Beans $(88 \mu \mathrm{g} \mathrm{Fe} / \mathrm{g})$ & - & 400 \\
Standard Beans $(59 \mu \mathrm{g} \mathrm{Fe} / \mathrm{g})$ & 400 & - \\
Corn & 350 & 350 \\
Corn oil & 30 & 30 \\
Dry skim milk & 100 & 100 \\
Corn starch & 46.75 & 46.75 \\
Vitamin/mineral premix (no Fe) ${ }^{1}$ & 70 & 70 \\
D-Methionine & 2.5 & 2.5 \\
Choline Chloride & 0.75 & 0.75 \\
Total (g) & 1000 & 1000 \\
Selected components & mean \pm SEM, $\mathrm{n}=5$ (by analysis) \\
Fe $\left(\mu \mathrm{g}\right.$ Fe/g) ${ }^{2}$ & $39.4 \pm 0.2^{\mathrm{b}}$ & $52.9 \pm 0.9^{\mathrm{a}}$ \\
Phytate:Fe molar ratio ${ }^{3}$ & $8.25 \pm 0.65^{\mathrm{a}}$ & $8.95 \pm 0.72^{\mathrm{a}}$ \\
\hline
\end{tabular}

${ }^{1}$ Vitamin and mineral premix provided/kg diet (330002 Chick vitamin mixture; 235001 Salt mix for chick diet; Dyets Inc. Bethlehem, PA).

${ }^{2}$ Iron concentrations in the diets were determined by an inductively-coupled argon-plasma/atomic emission spectrophotometer (ICAP 61E Thermal Jarrell Ash Trace Analyzer, Jarrell Ash Co. Franklin, MA) following wet ashing.

${ }^{3}$ Method for determining phytate contents are described in the materials and methods section

${ }^{a, b}$ Within a row, means without a common letter are different, $\mathrm{P}<0.05$.

and standard agronomic practices and shipped to Ithaca, New York in sealed containers imported as grain. Upon arrival, beans were rinsed in ultra-pure $(18 \Omega)$ water and then cooked (autoclaved for 45 minutes in water and until soft). Beans were then freeze-dried and milled prior to the mixing the diets (for all processing stainless steel appliances were used).

\section{Blood analysis and hemoglobin $(\mathrm{Hb})$ measurements}

Blood samples were collected weekly from the wing vein $(\mathrm{n}=14, \sim 100 \mu \mathrm{L})$ using micro-hematocrit heparinized capillary tubes (Fisher, Pittsburgh, PA). Samples were collected in the morning following an $8 \mathrm{~h}$ overnight fast. The samples were analyzed for hemoglobin $(\mathrm{Hb})$ concentration (see below). Body weights and hemoglobin concentrations were measured weekly.

Fe bioavailability was calculated as hemoglobin maintenance efficiency (HME) [5-9]:

$$
H M E=\frac{H b F e, m g(\text { final })-H b F e, m g(\text { initial })}{\text { Total Fe Intake, } m g} \times 100
$$

Where $\mathrm{Hb}-\mathrm{Fe}$ (index of $\mathrm{Fe}$ absorption) = total body hemoglobin Fe. Hb-Fe was calculated from hemoglobin concentrations and estimates of blood volume based on body weight (a blood volume of $85 \mathrm{~mL}$ per kg body weight is assumed) $[5-9,15,22]$ :

$$
\begin{aligned}
\mathrm{Hb}-\mathrm{Fe}(\mathrm{mg})= & \mathrm{B} . \mathrm{W} .(\mathrm{kg}) \times 0.085 \mathrm{~L} \mathrm{blood} / \mathrm{kg} \\
& \times \mathrm{Hb}(\mathrm{g} / \mathrm{L}) \times 3.35 \mathrm{mg} \mathrm{Fe} / \mathrm{g} \mathrm{Hb} .
\end{aligned}
$$

Fe intakes were calculated from feed intake data and Fe concentrations in the feed.

At the end of the experiment (day 42nd), birds were euthanized by carbon dioxide exposure. The digestive tracts and livers were quickly removed from the carcass and separated into various sections for tissue (small intestine and liver $\sim 1-2 \mathrm{~cm} ; \sim 2-3 \mathrm{~g}$, respectively). The samples were immediately frozen in liquid nitrogen, and then stored in a $-80^{\circ} \mathrm{C}$ freezer until analysis.

All animal protocols were approved by the Cornell University Institutional Animal Care and Use Committee.

Blood $\mathrm{Hb}$ concentrations were determined spectrophotometrically using the cyanmethemoglobin method (H7506-STD, Pointe Scientific Inc. Canton, MI) following the kit manufacturer's instructions.

\section{Isolation of total RNA}

Total RNA was extracted from $30 \mathrm{mg}$ of duodenal (proximal duodenum) tissue using Qiagen RNeasy Mini Kit (Qiagen Inc.,Valencia, CA) according to the manufacturer's protocol. All steps were carried out under RNase free conditions. RNA was quantified by absorbency at 260$280 \mathrm{~nm}$. Integrity of the $28 \mathrm{~S}$ and $18 \mathrm{~S}$ rRNA was verified by $1.5 \%$ agarose gel electrophoresis followed by ethidium bromide staining.

\section{DMT1, DcytB and ferroportin gene expression analysis}

As previously described [5-9,15,20,22], PCR was carried out with primers chosen from the fragments of chicken (Gallus gallus) duodenal and hepatic tissues [DMT1 gene (GeneBank database; GI 206597489) (forward: 5'-AGC CGT TCA CCA CTT ATT TCG-3'; reverse: 5'-GGT CCA AAT AGG CGA TGC TC-3'), DcytB gene (GI 20380692) (forward: 5' GGC CGT GTT TGA GAA CCA CAA TGT T-3'; reverse: 5'-CGT TTG CAA TCA CGT TTC CAA AGA T-3') and Ferroportin gene (GI 61098365) (forward: 5'-GAT GCA TTC TGA ACA ACC AAG GA'; reverse: 5'-GGA GAC TGG GTG GAC AAG AAC TC-3')]. Tissue-specific $18 \mathrm{~S}$ rRNA was used to normalize the results [(GI 7262899) (forward: 5' - CGA TGC TCT TAA CTG AGT-3'; reverse: 5'CAG CTT TGC AAC CAT ACT C-3')]. All PCR products were separated by electrophoresis on $2 \%$ agarose gel, stained with ethidium bromide, and quantified using the Quantity One 1-D analysis software (Bio-Rad, Hercules, CA).

\section{In-vitro iron bioaccessibility assessment}

An in vitro digestion/Caco-2 cell culture model [5-9,21,23,24] was used to assess in vitro Fe bioavailability. With this 
method, the cooked bean samples and the formulated diets were subjected to simulated gastric and intestinal digestion. Exactly $0.5 \mathrm{~g}$ of the freeze dried cooked beans and diets samples were utilized for each replication of the in vitro digestion process.

\section{Harvesting of Caco-2 cells for ferritin analysis}

The protocols used in the ferritin and total protein contents analyses of Caco- 2 cells were similar to those previously described [5-9,22,24]. Caco-2 cells synthesize ferritin in response to increases in intracellular iron concentration. Therefore, we used the ratio of ferritin/total protein (expressed as ng ferritin/mg protein) as an index of the cellular Fe uptake. All glassware used in the sample preparation and analyses was acid washed.

Ferritin and Fe in the liver, electrophoresis, staining and measurement of gels

Liver ferritin and liver Fe quantification were conducted as previously described $[7-9,22,25,26]$. The gels were scanned with Bio-Rad densitometer. Measurements of the bands were conducted using the Quantity-One 1-D analysis program (Bio-Rad, Hercules, CA). All tests were conducted in duplicates for each animal $(n=6)$.

\section{Polyphenol concentrations in diets}

The list of reported compounds was generated by comparing calculated masses of flavonoids and hydroxycinnamic acids reported to be present in common bean [27] with high accuracy mass/charge $(\mathrm{m} / \mathrm{z})$ data derived from analysis of black bean seed coats using our Ultra Performance Liquid Chromatography/ Mass Spectrometry (UPLC/MS) system and related software. The identities of matching compounds were confirmed by comparison with UPLC retention times of standards and were sorted by relative abundance using Waters Metabolynx $x^{\circ}$ software. Eight of the nine most abundant polyphenols indicated by this method were selected for quantitative comparison by the use of UPLC/MS and standard curves. Identification and quantification of the ninth (and second most abundant, possibly myricetin 3-o-glucoside), was not possible because there was no commercially available standard.

\section{Polyphenol extraction}

To one gram of ground bean material, $5 \mathrm{~mL}$ of methanol: water (50:50) was added. The slurry was vortexed for one minute, placed in a sonication water bath for 10 minutes, vortexed again for one minute, and centrifuged at $4000 \mathrm{xg}$ for 15 minutes. The supernatant was filtered with a $0.45 \mu \mathrm{m}$ syringe filter and stored for later use in a $-20^{\circ} \mathrm{C}$ freezer.

\section{LC/MS analysis}

Extracts were analyzed by LC-MS with an Acquity UPLC coupled to a Xevo G2 QTof spectrometer (Waters Corp.
Milford, MA). For LC analysis, $5 \mu \mathrm{L}$ samples of extract were injected and passed through a HSS C18 $1.8 \mu \mathrm{m}$ $2.1 \times 100 \mathrm{~mm}$ column (Waters ${ }^{\circ}$ ) at $0.4 \mathrm{~mL} / \mathrm{min}$. The mobile phase consisted of water with $0.1 \%$ formic acid (solvent A) and acetonitrile with $0.1 \%$ formic acid (solvent B). Polyphenols were eluted using linear gradients of 97.6 to $80 \% \mathrm{~A}$ in $2.5 \mathrm{~min}, 80$ to $60 \% \mathrm{~A}$ in $0.5 \mathrm{~min}, 60$ to $48 \% \mathrm{~A}$ in $2 \mathrm{~min}, 48$ to $5 \% \mathrm{~A}$ in $0.5 \mathrm{~min}, 5$ to $97.6 \% \mathrm{~A}$ in $1 \mathrm{~min}$, and a $0.5 \mathrm{~min}$ hold at $97.6 \%$ A. Electro Spray Ionization (ESI) mass spectrometry was performed in positive ionization mode with a scan speed of $5 \mathrm{scans} / \mathrm{sec}$ in the mass range from 50 to $1200 \mathrm{Da}$. Lock-mass correction was used, with leucineenkephalin as the external lock-mass standard. LC-MS data were analyzed by MassLynx ${ }^{\circ}$ software.

\section{Phytic acid analysis in diets}

Dietary phytic acid (phytate)/total phosphorus was measured as phosphorus released by phytase and alkaline phosphatase, following the kit manufacturer's instructions $(\mathrm{n}=5)(\mathrm{K}-\mathrm{PHYT} 12 / 12$, Magazyme International, Ireland).

\section{Statistical analysis}

Results were analyzed by ANOVA using the general linear models procedure of SAS software ${ }^{\bullet}$ (SAS Institute Inc. Cary, NC). Differences between treatments were compared by Tukey's test and values were considered statistically different at $\mathrm{P}<0.050$ (values in the text are means \pm SEM).

\section{Results}

Growth rates, hemoglobin $(\mathrm{Hb}), \mathrm{Hb} F e$ and $\mathrm{Hb}$ maintenance efficiency (HME)

There were no significant differences in feed intakes at any time throughout the study; thus, Fe intakes were consistently higher in the "Biofortified Fe" group vs. "Standard Fe" group (cumulative Fe intakes at week 6 were $166.8 \pm 17.8 \mathrm{mg}$ and $128.2 \pm 15.6 \mathrm{mg}$, for the "Biofortified Fe" group vs. "Standard Fe" group, respectively). Hemoglobin concentrations tended to be higher in the "Biofortified Fe" group vs. "Standard Fe" group, and was significantly higher at week $6(\mathrm{P}<0.05$; Figure 1). Significant differences were measured in HME on days 14, 21 and 28 of the experiment between the "Biofortified Fe" group vs. "Standard Fe" group (Figure 1). In addition, the increase in total body $\mathrm{Hb}$ Fe values at the end of the 6th week was significantly greater in the "Biofortified Fe" group vs. "Standard Fe" group (25.5 \pm $0.8 \mathrm{mg}$ and $23.3 \pm 0.6 \mathrm{mg}$, respectively, $\mathrm{P}<0.05$, Figure 1$)$.

\section{Gene expression of iron transporters (DMT-1, Ferroportin) and DcytB in the duodenum}

Gene expression analysis of duodenal DMT-1, Ferroportin and DcytB, with results reported relative to $18 \mathrm{~S}$ rRNA, indicated no significant differences in mRNA expression of DMT1, DcytB and ferroportin between treatment groups $(\mathrm{n}=6, \mathrm{P}>0.05)$. 

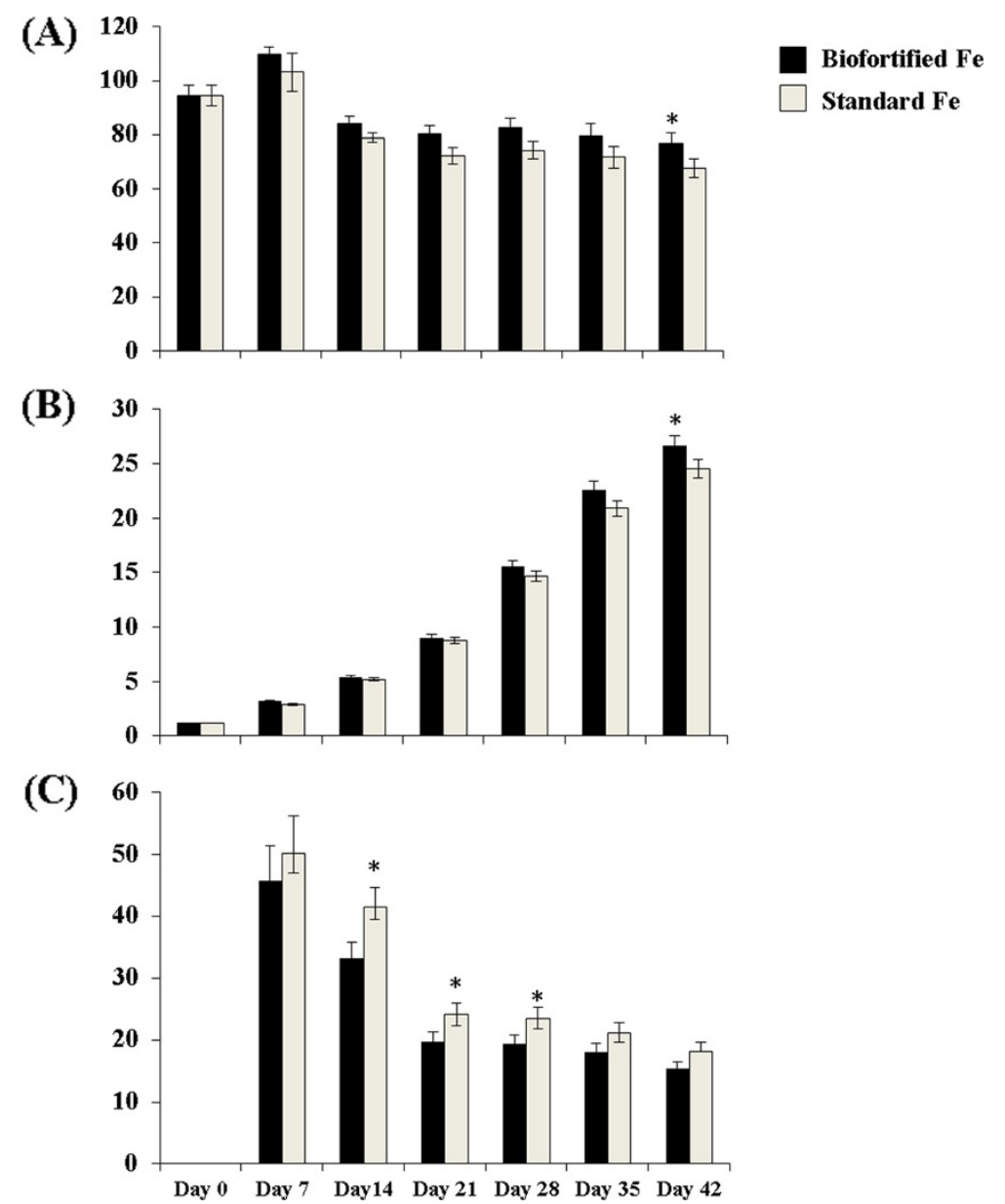

Figure 1 (A) Hemoglobin (g/L), (B) Total body Hb Fe content (mg), and (C) Hemoglobin maintenance efficiency (HME, \%), in chicken fed the tested diets from $\mathbf{d} \mathbf{0}$ to $\mathbf{d} \mathbf{4 2}^{1}$. ${ }^{*} P<0.05$. ${ }^{1}$ Values are means $\pm S E M, n=14$. ${ }^{2}$ Values are mean daily feed intakes for the 7 days proceeding the day designated in the column heading. ${ }^{3}$ Values are mean \pm SEM (cumulative weekly from day 0). ${ }^{4,5} \mathrm{Fe}$ bioavailability was calculated as hemoglobin maintenance efficiency (HME) [5-9,15]: HME $=\frac{\mathrm{Hb} \mathrm{Fe}, \mathrm{mg}(\text { final) }-\mathrm{Hb} F e, \mathrm{mg} \text { (initial) }}{\text { Total Fe Intake, } \mathrm{mg}} \times 100$. Where $\mathrm{Hb}$-Fe $=$ total body hemoglobin Fe. Hb Fe was calculated from hemoglobin concentrations and estimates of blood volume based on body weight (a blood volume of $85 \mathrm{~mL}$ per kg body weight is assumed) $[5-9,15,22]: \mathrm{Hb}-\mathrm{Fe}(\mathrm{mg})=$ B. W. $(\mathrm{kg}) \times 0.085 \mathrm{~L} \mathrm{blood} / \mathrm{kg} \times \mathrm{Hb}(\mathrm{g} / \mathrm{L}) \times 3.35 \mathrm{mg} \mathrm{Fe} / \mathrm{g} \mathrm{Hb}$.

\section{Caco-2 cell ferritin formation}

An in vitro digestion/Caco-2 cell culture model was used to evaluate Fe bioavailability from the test diets by measuring ferritin formation in the cells (ie. a measure of cell Fe uptake) following exposure to digests of the samples. Ferritin concentrations, which are the measure of Fe uptake and bioavailability in this model, were not different in cells exposed to the "Biofortified Fe" vs. "Standard Fe" beans only and bean based diets $(n=6$, Table 2$)$.

\section{Ferritin and iron in the liver}

The avian ferritins corresponded to a weight of approximately 470 to $500 \mathrm{kDa}$ [7-9,24-26,28]. No significant differences in liver $\mathrm{Fe}$ or liver ferritin concentrations were measured between the treatment groups $(n=6, P>0.05)$. The mean values of ferritin protein and the amount of
Table 2 Ferritin concentrations in Caco-2 cells exposed to samples of beans only (whole bean) and bean-based diets

\begin{tabular}{|c|c|}
\hline Tested sample ${ }^{1}$ & Ferritin ( $\mathrm{ng} / \mathrm{mg}$ of protein) \\
\hline "Standard Fe" bean only (59 $\mu \mathrm{gFe} / \mathrm{g}$ bean) & $2.31 \pm 0.11^{c}$ \\
\hline 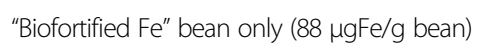 & $2.19 \pm 0.14^{c}$ \\
\hline $\begin{array}{l}\text { "Standard Fe" bean-based diet } \\
(39 \mu \mathrm{gFe} / \mathrm{g} \text { diet) }\end{array}$ & $2.97 \pm 0.10^{b}$ \\
\hline $\begin{array}{l}\text { "Biofortified Fe" bean-based diet } \\
\text { ( } 53 \text { } \mathrm{gFe} / \mathrm{g} \text { diet })\end{array}$ & $2.75 \pm 0.09^{b}$ \\
\hline Baseline $^{2}$ & $3.28 \pm 0.139^{a}$ \\
\hline
\end{tabular}

${ }^{1}$ Caco- 2 bioassay procedures and preparation of the digested samples are described in the materials and methods sections.

${ }^{2}$ Cells were exposed to only MEM growth media without added food digests and Fe. Values are means $\pm S E M, n=6$.

$\mathrm{a}, \mathrm{b}, \mathrm{c}$ Within a column, means without a common letter are different, $\mathrm{P}<0.05$. 
iron present in the ferritin of the liver samples of all animals are presented in Table 3.

\section{Total phenolic concentration in the diet sample}

Concentrations of the polyphenols known to be most prevalent in black beans were measured and are shown in Table 4. Overall it appears that kaempferol, epicatechin, myricetin, kaempferol 3-glucoside, and quercitin 3-glucoside were significantly higher in the high Fe beans.

\section{Phytate:Fe molar ratios in the diet samples}

The concentrations of phytic acid $\left(\mathrm{IP}_{1-6}\right)$ and Fe in the diets were used to calculate the phytate to Fe molar raios. The ratios of phytate:Fe did not differ between diets and were $8.25 \pm 0.65$ and $8.95 \pm 0.72$ for the "Standard Fe" and "biofortified-Fe" bean based diets, respectively $(\mathrm{n}=5$; $\mathrm{P}>0.05$, Table 1).

\section{Discussion}

In terms of biofortification, target levels for bean $\mathrm{Fe}$ concentration have been set at approximately $90 \mu \mathrm{g} / \mathrm{g}$ or higher, which should likely represent a $40 \mu \mathrm{g} / \mathrm{g}$ differential from more typical common bean Fe levels [29,30]. That target value is based on calculations that assume the percent bioavailability of the $\mathrm{Fe}$ is similar between the normal and enhanced lines, hence delivering more absorbable Fe. This assumption is potentially disastrous in terms of planning and ultimately moving forward with a human efficacy trial, as such trials can easily cost $\$ 500,000$ or more. Given this expense, it is prudent to utilize inexpensive screening tools that are validated to predict relative differences in Fe bioavailability.

A strong case can now be made for utilizing the widely accepted and inexpensive in vitro digestion/Caco-2 cell culture model to determine if biofortified lines warrant advancement to human study [7-9]. Furthermore, this in vitro approach has recently been coupled with a poultry model for Fe bioavailability and it has confirmed the in vitro predictions [7-9]. Such observations certainly provide confidence in advancing lines for the more expensive human trials. If consistent correlations between these screening tools and human results can be established, then future work can be guided by these models thus enhancing the effectiveness of research

Table 3 Ferritin protein and the iron ${ }^{1}$ concentration in the liver

\begin{tabular}{llll}
\hline $\begin{array}{l}\text { Treatment } \\
\text { diet }\end{array}$ & $\begin{array}{l}\text { Ferritin } \\
\boldsymbol{\mu g} / \mathbf{g} \text { wet weight }\end{array}$ & $\begin{array}{l}\text { Iron } \\
\boldsymbol{\mu g} / \mathbf{g} \text { wet weight }\end{array}$ & $\begin{array}{l}\text { Iron/Ferritin } \\
\boldsymbol{\mu m o l}\end{array}$ \\
\hline "Biofortified $\mathrm{Fe} "$ & $293 \pm 11^{\mathrm{a}}$ & $33.1 \pm 2.2^{\mathrm{a}}$ & $45.6 \pm 3.5^{\mathrm{a}}$ \\
"Standard $\mathrm{Fe} "$ & $282 \pm 12^{\mathrm{a}}$ & $27.2 \pm 1.7^{\mathrm{a}}$ & $39.8 \pm 4.2^{\mathrm{a}}$ \\
\hline
\end{tabular}

${ }^{1}$ Atomic mass for iron is $55.8 \mathrm{~g} / \mathrm{mol}$.

${ }^{a}$ Values are mean $\pm S E M, n=14$. Within a column, means without a common letter are different, $\mathrm{P}<0.05$.
Table 4 Concentrations of the most prevalent polyphenols observed in the black beans ${ }^{1}$ ( $\mathrm{nmol} / \mathrm{g}$ )

\begin{tabular}{lll}
\hline Compound & “Biofortified Fe" & "Standard Fe" \\
\hline Caffeic acid & $6.0 \pm 0.9^{\mathrm{b}}$ & $25.8 \pm 4.7^{\mathrm{a}}$ \\
Gallic acid & $125.0 \pm 8.8^{\mathrm{a}}$ & $103.3 \pm 17.8^{\mathrm{a}}$ \\
Ferulic acid & $153.0 \pm 11.1^{\mathrm{a}}$ & $162.5 \pm 20.1^{\mathrm{a}}$ \\
Kaempferol & $5.0 \pm 0.1^{\mathrm{a}}$ & $0.00 \pm 0.00^{\mathrm{b}}$ \\
Catechin & $668.8 \pm 31.1^{\mathrm{a}}$ & $367.5 \pm 25.5^{\mathrm{b}}$ \\
Myricetin & $24.0 \pm 1.7^{\mathrm{a}}$ & $12.5 \pm 4.0^{\mathrm{b}}$ \\
Kaempferol 3-glucoside & $198.0 \pm 10.7^{\mathrm{a}}$ & $19.2 \pm 5.6^{\mathrm{b}}$ \\
Quercetin 3-glucoside & $239 \pm 20.3^{\mathrm{a}}$ & $45.8 \pm 7.9^{\mathrm{b}}$ \\
\hline
\end{tabular}

${ }^{1}$ Analysis procedures of beans samples are described in the materials and methods sections.

$a, b$ Within a row, means without a common letter are different $(n=6, P<0.05)$.

dollars. Moreover, such lines will have to be monitored once released, and these models represent tools that will be needed to do so.

In the present study, the in vitro results predicted that the biofortified (high Fe) bean will not provide additional absorbable Fe. The in vivo results reflect this prediction, as no significant differences in liver ferritin and liver $\mathrm{Fe}$ were observed, and only slight differences were observed in $\mathrm{Hb}$ (higher only on day 42 in the high Fe bean group) and total body $\mathrm{Hb}$ (also higher on day 42 for the high Fe bean group). Hemoglobin maintenance efficiency was higher in the low Fe group at days 14th, 21st and 28th, indicating an adaptive response (ie. a relative up regulation of absorption) to less absorbable dietary Fe. The duodenal relative mRNA abundance analysis of DMT-1, DcytB and ferroportin that showed no significant differences between the standard (Low $\mathrm{Fe}$ ) group vs. the biofortified (High Fe) group $(\mathrm{P}>0.05)$, suggests a lower dietary Fe bioavailability in both groups [5-9]. Taken together, all of the above mentioned measures of Fe status indicate that the two dietary treatment groups were of relatively similar Fe status, with only a hint of more absorbable Fe being provided by the high Fe black beans.

The strong inhibition of Fe uptake reflected in the in vitro results is typical of a strong polyphenolic inhibition of Fe bioavailability. Similar results (ie. when the Caco-2 cell ferritin formation is at or below the untreated baseline values), have been seen many times in the use of this in vitro model $[7,8,21]$. The polyphenolic profile and measurement of concentration indicates that the high Fe beans were also higher in polyphenolic content, specifically, catechin, myricetin, kaempferol 3-glucoside and quercetin 3-glucoside (Table 4), than the low Fe beans. Thus it appears that the potential nutritional benefit from the higher Fe content was offset by the increased levels of polyphenolics. These observations clearly suggest that further research should be done to explore the metabolic and potential genetic link between Fe content and polyphenols. 
A wealth of information is available on the phenolic and polyphenolic profile of foods [31-34], and specifically in regards to beans $[27,35]$. In addition, there are a considerable number of papers that focus on the Fe-binding properties of polyphenols as related to antioxidation [36]. Perron et al. [37] investigated the kinetics of Fe oxidation upon binding to polyphenols and observed that gallolcontaining polyphenols have faster rates of Fe oxidation (ie. $\mathrm{Fe}^{+2}$ to $\mathrm{Fe}^{+3}$ ) than their catechol analogs. This faster rate of oxidation was believed to be related to the strength of the Fe binding. Thus, compounds such as epicatechin and quercitin would be expected to have slower rates of Fe oxidation and less strength of Fe binding than their respective gallol analogs, epigallocatechin and myricitin. These differences could be translated into different effects on Fe bioavailability as greater oxidation and stronger binding of $\mathrm{Fe}$ is generally correlated with lower bioavailability. However it is important to note that in the above studies, conditions for the measured reactions were not designed to match the conditions of the intestinal lumen, hence the oxidation and binding of Fe could differ.

In regards to Fe bioavailability there is clear evidence that polyphenolic compounds related to seed coat color in beans have a strong inhibitory effect on Fe bioavailability. Several in vitro and in vivo studies have demonstrated that Fe bioavailability from black, red and pinto beans is significantly less than that of white beans $[5-8,21,38]$. To date there has only been one published study that has linked specific bean seed coat polyphenols to inhibition of Fe bioavailability [38]. In that study the flavonoids kaempferol and quercitin identified in red, pinto and black bean hulls were shown to inhibit Fe bioavailability. This work did not exclude any other compounds from having an effect on Fe bioavailability, it merely documented inhibitory effects of these compounds which were found in high quantities in the red and pinto bean seed coats, to a lesser extent in black beans, and absent from white beans.

An interesting study by Lin et al. [27] profiled but did not quantify the polyphenolics in 24 bean samples representing 17 varieties and 7 "generic off the shelf" samples, with the total group belonging to 10 commercial US market classes. Their work showed that the beans could be organized into 6 classes based on their polyphenolic profiles. The classes were black, pinto, pink, light red kidney bean, small red and navy. In general, these groups contained similar hydroxycinnaminic acid derivatives as their main phenolic profile with the flavonoid content less prominent but more varied and distinctive for each group. For each group there were 10 or less flavonoid compounds that were predominant. If one were to screen these for effects on Fe bioavailability then certainly a relatively high throughput system would be needed, as concentration and interactive effects would also need to be considered. In our opinion, the in vitro digestion/ Caco-2 model [23] or a variation thereof is capable of performing this work.

Recently, we were able to demonstrate that specific polyphenols found in black bean seed coats are inhibitors of Fe uptake whereas others are promoters of Fe uptake [39]. This work uses a modification of the in vitro digestion/Caco-2 cell model [23] and LC/MS to measure relative amounts of flavonoids and hydroxycinnamic acids in black bean seed coats that were previously identified as major polyphenolic components of common bean [27]. The aforementioned research has enabled us to generate a key list of phenolic and polyphenol compounds in black beans that predominate and may be related to Fe bioavailability. Those compounds are reported in Table 4. Comparisons of the polyphenols between the two lines used in this study certainly indicate that the higher polyphenols in the high Fe line may have negated the nutritional benefit of higher Fe. These differences could be environmental in origin, or possibly linked to the effort to breed for higher Fe. Regardless, these results indicate that the polyphenolic profile of beans should be considered for future human efficacy studies of high Fe beans.

The list of polyphenols and flavonoids reported here represent the predominant compounds that were detected in the tested black beans, however, these compounds are part of a major group of compounds observed in black beans as previously reported [27]. As it was shown before, several of the detected compounds present $\mathrm{Fe}^{+3}$ binding ability that results in decreased Fe bioavailability and absorption [34-37,40]. For example, quercetin, which is one of the most common flavonols present in nature and is the predominant flavonoid in the diet, and was detected in increased concentrations in the biofortified Fe bean variety. Quercetin was shown to be a strong $\mathrm{Fe}^{+3}$ chelator, hence, suggested to decrease Fe bioavailability in foods [40]. In addition the compound catechin, that was also detected in increased concentration in the biofortified Fe bean variety was also reported to have strong binding affinity to $\mathrm{Fe}^{+3}$, specifically in a less acidic environment, as in the duodenum where most absorption of Fe occurs [41]. Increased concentrations of kaempferol 3-glucoside were also detected in the biofortified Fe black bean variety. Previously, it was demonstrated that kaempferol 3-glucoside in red and pinto bean seed inhibited Fe bioavailability in vitro [38]. Thus, seed coat kaempferol was identified as a potent inhibitory factor affecting iron bioavailability in the red and pinto beans studied. Results comparing the inhibitory effects of kaempferol, quercitrin, and astragalin on iron bioavailability suggest that the $3^{\prime}, 4^{\prime}$-dihydroxy group on the B-ring in flavonoids contributes to the lower iron bioavailability [38]. 
In summary, the current study suggests that increasing Fe concentrations in black beans by about $30 \mu \mathrm{g} / \mathrm{g}$ provides a very small increase in the amount of bioavailable and therefore absorbable $\mathrm{Fe}$ in vivo. The increased polyphenol concentration in the high Fe beans indicates that these compounds must also be considered when advancing high Fe lines for human studies in order to achieve significant nutritional benefits.

\section{Conclusion}

Based on the data shown here, the in vivo results suggested a relatively small nutritional benefit to the biofortified bean variety. Evidence suggests that the nutritional benefit of the biofortified beans is reduced by the presence of polyphenols. Hence, modification of the bean seed coat polyphenols may be a means to improve bean Fe bioavailability. We conclude that biofortified black beans remain are a promising vehicle for increasing intakes of bioavailable $\mathrm{Fe}$ in populations that consume these beans as a dietary staple. However, the bean polyphenols profile must be further evaluated in order to improve the nutritional benefit of beans.

\section{Endnotes}

Mention of a trademark, proprietary product or vendor does not constitute a guarantee or warranty of the product by the United states Department of Agriculture and does not imply its approval to the exclusion of other products or vendors that may also be suitable.

\section{Abbreviations \\ Fe: Iron; Hb: Hemoglobin; Hb- Fe: Hemoglobin iron; HME: Hemoglobin maintenance efficiency; BW: Body weight; CIAT: Centro Internacional de Agricultural Tropical; PCR: Polymerase chain reaction; DMT-1: Divalent metal transporter 1; DcytB: Duodenal cytochrome B; Da: Dalton; MEM: Minimum essential media.}

\section{Competing interests}

The authors declare that they have no competing interests.

\section{Authors' contributions}

ET was a co-principal investigator in developing the study protocol and design, performing the data collection, statistical analyses, in vivo and in vitro analyses, and writing of the manuscript. SB provided the bean lines used in the study. SR assisted with the in vivo data collection and analysis. $J H$ performed the polyphenolic bean analysis. RG was a co-principal investigator who participated in the study design, in vivo and in vitro analyses, and edited the manuscript. All authors approved the final manuscript.

\section{Acknowledgements}

We thank Mrs. Pei-pei Chang and Mrs. Mary Bodis for their excellent technical support in the USDA Nutrition laboratory.

\section{Author details}

${ }^{1}$ USDA/ARS, Robert W. Holley Center for Agriculture and Health, Cornell University, Ithaca, NY 14853, USA. ${ }^{2}$ CIAT- International Center for Tropical Agriculture, Cali, Colombia. ${ }^{3}$ Department of Plant Biology, Cornell University, Ithaca, NY 14853, USA.

Received: 12 November 2013 Accepted: 24 March 2014

Published: 26 March 2014

\section{References}

1. WHO: Iron Deficiency Anemia Assessment, Prevention and Control. A Guide for Program Managers. Geneva: WHO/NDH; 2001:15-21.

2. Nestel P, Bouis HE, Meenakshi JV, Pfeiffer W: Biofortification of staple food crops. J Nutr 2006, 136:1064-1067.

3. Bouis HE: Plant breeding: a new tool for fighting micronutrient malnutrition. J Nutr 2002, 132:S491-S494.

4. Carlson D, Nørgaard JV, Torun B, Cakmak I, Poulsen HD: Bioavailability of trace elements in beans and zinc-biofortified wheat in pigs. Biol Trace Elem Res 2012, 150(1-3):147-153.

5. Tako E, Laparra M, Glahn RP, Welch RM, Lei X, Beebe S, Miller D: Biofortified black beans in a maize and bean diet provide more bioavailable iron to piglets than standard black beans. J Nutr 2009, 139:305-309.

6. Tako E, Glahn RP, Laparra JM, Welch RM, Lei X, Kelly JD, Rutzke MA, Miller DD: Iron and zinc bioavailabilities to pigs from red and white beans (Phaseolus vulgaris L.) are similar. J Agric Food Chem 2009, 57:3134-3140.

7. Tako E, Glahn RP: White beans provide more bioavailable iron than red beans: studies in poultry (Gallus gallus) and an in vitro digestion/Caco-2 model. Int J Vitam Nutr Res 2011, 81(1):1-14.

8. Tako E, Blair MW, Glahn RP: Biofortified red mottled beans (Phaseolus vulgaris L.) in a maize and bean diet provide more bioavailable iron than standard red mottled beans: Studies in poultry (Gallus gallus) and an in vitro digestion/Caco-2 model. Nutr J 2011, 10:113.

9. Tako E, Hoekenga OA, Kochian LV, Glahn RP: High bioavailablilty iron maize (Zea mays L.) developed through molecular breeding provides more absorbable iron in vitro (Caco-2 model) and in vivo (Gallus gallus). Nutr J 2013, 12:3.

10. De Rosa MC, Carelli Alinovi C, Galtieri A, Scatena R, Giardina B: The plasma membrane of erythrocytes plays a fundamental role in the transport of oxygen, carbon dioxide and nitric oxide and in the maintenance of the reduced state of the heme iron. Gene 2007, 398(1-2):162-171.

11. Neumann CG, Gewa C, Bwibo NO: Child nutrition in developing countries. Pediatr Ann 2004, 33(10):658-674.

12. Baltussen $\mathrm{R}$, Knai $\mathrm{C}$, Sharan M: Iron fortification and iron supplementation are cost-effective interventions to reduce iron deficiency in four subregions of the world. J Nutr 2004, 134(10):2678-2684.

13. Brinch-Pedersen H, Sørensen LD, Holm PB: Engineering crop plants: getting a handle on phosphate. Trends Plant Sci 2002, 7(3):118-125

14. Lung'aho MG, Mwaniki AM, Szalma SJ, Hart JJ, Rutzke MA, Kochian LV, Glahn RP, Hoekenga OA: Genetic and physiological analysis of iron biofortification in maize kernels. PLoS One 2011, 6(6):20429.

15. Tako E, Rutzke MA, Glahn RP: Using the domestic chicken (Gallus gallus) as an in vivo model for iron bioavailability. Poult Sci 2010, 89:514-521.

16. Welch RM, House WA, Beebe S, Cheng Z: Genetic selection for enhanced bioavailable levels of iron in bean (Phaseolus vulgaris L.) seeds. J Agric Food Chem 2000, 48(8):3576-3580.

17. Geil PB, Anderson JW: Nutrition and health implications of dry beans: a review. J Am Coll Nutr 1994, 13:549-558.

18. Petry N, Egli I, Zeder C, Walczyk T, Hurrell R: Polyphenols and phytic acid 41-43contribute to the low iron bioavailability from common beans in young women. J Nutr 2010, 140(11):1977-1982.

19. Welch RM, House WA, Beebe S, Senadhira D, Gregorio G, Cheng Z: Testing iron and zinc bioavailability in genetically enriched beans (Phaseolus vulgaris L.) and rice (Oryza sativa L.) using a rat model. Food Nutr Bull 2000, 21(4):428-433.

20. Blair MW, Medina Jl, Astudillo C, Rengifo J, Beebe SE, Machado G, Graham R: QTL for seed iron and zinc concentration and content in a Mesoamerican common bean (Phaseolus vulgaris L.) population. Theor Appl Genet 2010, 121(6):1059-1070.

21. Ariza-Nieto M, Blair MW, Welch RM, Glahn RP: Screening of iron bioavailability patterns in eight bean (Phaseolus Vulgaris L.) genotypes using the Caco-2 cell in vitro model. J Agric Food Chem 2007, 55:7950-7956.

22. Tako E, Glahn RP: Iron Status of the Late Term Broiler (Gallus gallus) Embryo and Hatchling. Int J Poul Sci 2011, 10(1):42-48.

23. Glahn RP, Lee OA, Yeung A, Goldman Ml: Caco-2 Cell ferritin formation predicts nonradiolabeled food iron availability in an in vitro digestion/ Caco-2 Cell culture model. J Nutr 1998, 128(9):1555-1561.

24. Etcheverry PD, Miller DD, Glahn RP: A low-molecular weight factor in human milk whey promotes iron uptake by Caco-2 cells. J Nutr 2004, 134:93-98.

25. Mete A, Van Zeeland YR, Vaandrager AB, van Dijk JE, Marx JJ, Dorrestein GM: Partial purification and characterization of ferritin from the liver and 
intestinal mucosa of chickens, turtledoves and mynahs. Avian Pathol 2005, 34(5):430-434.

26. Passaniti A, Roth TF: Purification of chicken liver ferritin by two novel methods and structural comparison with horse spleen ferritin. J Biochem 1989, 258:413-419.

27. Lin LZ, Harnly JM, Pastor-Corrales MA, Luthria DL: The polyphenolic profiles of common bean (Phaseolus Vulgaris L.). Food Chem 2008, 107:399-410.

28. Yang CS, Landau JM, Huang MT, Newmark HL: Inhibition of carcinogenesis by dietary polyphenolic compounds. Annu Rev Nutr 2001, 21:381-406.

29. Blair MW, Astudillo C, Beebe SE, Roa I, Kimani P, Chirwa R: Biofortification breeding of common bean (Phaseolus vulgaris L.). Biozoom 2009, 1:25-28.

30. Beebe S: Common Bean Breeding in the Tropics. In Plant Breeding Reviews, Volume 36, Ch 5. Edited by Janick J. Hoboken, NJ, USA: Wiley; 2012.

31. Gu L, Kelm MA, Hammerstone JF, Beecher G, Holden J, Haytowitz D, Prior RL: Screening of foods containing proanthocyanidins and their structural characterization using LC-MS/MS and thiolytic degradation. J Agric Food Chem 2003, 3:51(25):7513-7521.

32. Tsao R, Yang R, Young JC, Zhu H: Polyphenolic profiles in eight apple cultivars using high-performance liquid chromatography (HPLC). J Agri Food Chem 2003, 51(21):6347-6353.

33. Vallverdú-Queralt A, Odriozola-Serrano I, Oms-Oliu G, Lamuela-Raventós RM, Elez-Martínez P, Martín-Belloso O: Changes in the polyphenol profile of tomato juices processed by pulsed electric fields. J Agri Food Chem 2012, 60(38):9667-9672.

34. Manach C, Scalbert A, Morand C, Rémésy C, Jiménez L: Polyphenols: food sources and bioavailability. Am J Clin Nutr 2004, 79(5):727-747.

35. Luthria DL, Pastor-Corrales MA: Phenolic acids of fifteen dry edible bean (Phaseolus Vulgaris L.) varieties. J Food Comp Anal 2006, 19:205-211.

36. Perron NR, Brumaghim $J$ : A review of the antioxidant mechanisms of polyphenol compounds related to iron binding. Cell Biochem Biophys 2009, 53:75-100.

37. Perron NR, Wang HC, Deguire SN, Jenkins M, Lawson M, Brumaghim JL: Kinetics of iron oxidation upon polyphenol binding. Dalton Trans 2010, 7;39(41):9982-9987.

38. Hu Y, Cheng Z, Heller LI, Krasnoff SB, Glahn RP, Welch RM: Kaempferol in red and pinto bean seed (Phaseolus vulgaris L.) coats inhibits iron bioavailability using an in vitro digestion/human Caco-2 cell model. J Agric Food Chem 2006, 54(24):9254-9261.

39. Hart JJ, Glahn RP: Identification of bean polyphenols that inhibit and enhance iron uptake by Caco-2 cells. FASEB J 2013, 27(Meeting Abstract Supplement):634.13.

40. Ryan $P$, Hynes MJ: The kinetics and mechanisms of the reactions of iron (III) with quercetin and morin. J Inorg Biochem 2008, 102(1):127-136.

41. Hynes MJ, Coinceanainn MO: The kinetics and mechanisms of the reaction of iron(III) with gallic acid, gallic acid methyl ester and catechin. J Inorg Biochem 2001, 85(2-3):131-142.

doi:10.1186/1475-2891-13-28

Cite this article as: Tako et al:: Polyphenolic compounds appear to limit the nutritional benefit of biofortified higher iron black bean (Phaseolus vulgaris L.). Nutrition Journal 2014 13:28.

\section{Submit your next manuscript to BioMed Central and take full advantage of:}

- Convenient online submission

- Thorough peer review

- No space constraints or color figure charges

- Immediate publication on acceptance

- Inclusion in PubMed, CAS, Scopus and Google Scholar

- Research which is freely available for redistribution

Submit your manuscript at www.biomedcentral.com/submit
( Biomed Central 